\title{
Kant y la Metafísica
}

"Tiene la razón humana el singular destino, en cierta especie de conocimientos, de verse agobiada por cuestiones de índole tal que no puede evitarlas, porque su propia naturaleza las crea, y que no puede resolver porque a su alcance no se encuentran".

Así comienza Kant el Prefacio a la Primera Edición de su Obra, y en este primer párrafo parécenos que ha sintetizado admirablemente su pensamiento, tal como fluía en la recóndita intimidad de su ser.

Entre las diversas interpretaciones que se han hecho o pueden hacerse acerca de la obra de Kant, nosotros creemos encontrar lo fundamental y esencial de su pensamiento, en la "Crítica de la Razón Práctica", parte en la que precisamente trata de esas "cuestiones de índole tal..." que están más allá de toda cexperiencia posible, y que constituyen, por tanto, el campo de la METAFISICA

Para fundamentar nuestra posición, intentaremos un ensayo de penetración en la profundidad de la naturaleza humana, porque es de esa pasta de la que están hechos los filósofos. El filósofo es ante todo un hombre, y la Filosofía brota del hombre como la flor o el fruto brota de la planta.

Se ha tratado de caracterizar al hombre (y tal vez Kant es uno de los que con más agudeza así lo hizo), desde el punto de vista de la RAZON. Pero esta posición, por muy racional que fuera, es sólo teorética y por consiguiente unilateral. En realidad lo que da sentido a una vida humana es un principio de unidad; en la raíz misma de la vida encontramos el SENTIMIENTO y la VOLUNTAD como fuerzas primarias, germinales, de esa unidad.

Pues bien: creemos que las concepciones racionales o intelectuales, son algo así como una consecuencia del íntimo sentir y querer de los 
hombres. Muchos tratarán de demostrar lo contrario, pero acaso sin saberlo, estarán revelando, en su misma "imparcialidad emotiva", un interés que consciente $o$ inconscientemente los mueve en su razonamiento.

Es pues ese trágico anhelo de conocerlo todo, esa aspiración a lo absoluto, esa eterna curiosidad vital, lo que estimula a la razón (y aquí está el origen de "la propia naturaleza" de là razón humana) a buscar una explicación a todas las cosas, una explicación unitaria de nuestra propia vida y de la vida del mundo. No se trata pues, sino de buscar un asidero, una tabla de salvación a nuestro más hondo anhelo vital.

$Y$ este es el "singular destino" de la razón humana, y por eso dice Kant que "no se halla en esa situación por culpa suya".

Mientras no salimos del campo empírico, no hay dificultad para la razón, pero poco a poco va elevándose, de los efectos a las causas, y de éstas, convertidas a su vez en efectos, a otras causas más generales, y así en una gradación ascencional sin término...

Pero como la razón tiene necesidad de un principio absoluto que explique la totalidad del Universo y de la Vida, sin que ya nada sobre él sea capaz de determinarlo, se ve obligada a refugiarse en principios supra-sensibles, que ella misma, la razón, no puede demostrar "porque a su alcance no se encuentranë.

Es el problema trágico de la razón humana: estar condenada a "no poder evitar estas cuestiones", Y condenada también a no poder resolverlas jamás.

Y aquí estamos ya en la interioridad más difícil de la Metafísica de todos los tiempos, "en el corazón mismo de la Metafísica" como diría Bergson.

Es este el momento en que hacemos la presentación de Kant; de Kant metafísico; de Kant aquejado, aguijoneado trágicamente por el problema, por el eterno problema...

Será entonces el filósofo metafísico, antes que el filósofo especulativo, el que emprenderá la gran tarea especulativa (¿paradoja?) y demoledora de la "Crítica de la Razón Pura", para dejar preparado, abierto. limpio, el campo, a la obra fundamental y edificadora de la "Crítica de la Razón Práctica". 
Al criticar, Kant, la facultad misma de conocer, encuentra que la razón está fatalmente condicionada por las CATEGORIAS, las que a su vez limitan su acción únicamente al campo de la EXPERIENCIA. Resultará así una Metafísica en su Primera Parte (que propiamente no es $\mathrm{Me}$ tafísica sino Teoría del Conocimiento Científico): la Metafísica de los juicios sintéticos a priori, "considerada como "el Inventario sistemáticamente ordenado de todo lo que poseemos mediante la Razón pura"; es decir una Metafísica condenada a no pasar nunca los límites de la experiencia.

Pero desautorizado como ilegítimo todo intento de las categorías para invadir el campo de lo supra-sensible, queda la posibilidad de un uso no teorético de la razón, y así será la "Crítica de la Razón Práctica", la que se apodere del campo auténticamente metafísico. Será esta Metafísica de lo supra-sensible, la que hará realidad el "Noumeno" mediante la fe.

Lo real es el "NOUMENO". Algo más: todo lo que se nos da en el mundo de la experiencia, no será sino apariencia, conjunto de fenómenos.

Dicho en otros términos: este mundo sensible que de primera intención se nos ocurre lo más consistente o real, este mundo de la experiencia sobre el cual la razón especula, no sería sino un mundo de apariencias, algo así como un mundo de sombras, sin existencia real. Lo real, lo verdaderamente real, el "noumeno", está más allá de la experiencia, en el campoladonde nicla razón nela ciencia podrían llegar jamás.

Entonces nuestro saber; saber condicionado fatalmente a las categorías, el saber científico, no es sino un saber de fenómenos, de apariencias. El otro saber; el saber que ilegítimamente ha pretendido penetrar en una esfera para la cual no nació, el saber metafísico, ha sido destruído por Kant; por eso dirá en el Prólogo de la Segunda Edición de su obra: "Tuve pues que anular el SABER, para reservar un sitio a la FE".

Así ha salvado Kant el campo de lo supra-sensible; la esfera del Alma, del Mundo y de Dios; la esfera de la eterna Metafísica, de la Metafísica de la Razón Práctica, la que primordialmente interesa al espíritu humano. Con la fe se hace real ese mundo noumenal: se inmortaliza el ALMA, adquiere sentido el MUNDO, y se siente a DIOS; a ese Dios vivo, que rige nuestro destino, mantiene nuestra esperanza y nos hace vivir. 
La razón pura, la del otro campo, no podrá oponerse a lo pensado sin contradicción ,no podrá demostrar la imposibilidad de las realidades de la fe.

Pero, ¿existe contradicción entre la razón y la fe? Difícil tarea es por cierto, para el hombre, querer armonizar las necesidades del intelecto con los anhelos del corazón: el uno tiene una ansia infinita de vida, $y$ el otro martillea sin piedad este anhelo vital. Es una trágica contradicción la que existe, pero una contradicción que fundamenta la vida y le da unidad.

$Y$ en el pensamiento kantiano, ¿existe contradicción entre la "Crítica de la Razón Pura" y la "Crítica de la Razón Práctica"?

- Como que la una es pensamiento puro, especulativo y demoledor, y la otra es emoción edificadora, esperanzada y anhelante, SI. Pero como obra, la primera, que abre y prepara el camino a la segunda, NO.

- Como depuradora, la primera, de la Metafísica en su Primera Parte (Teoría del Conocimiento Científico), y como salvadora, la segun da, de la Metafísica en su Segunda Parte (esfera del Mundo, del Alma y de Dios), SI. Pero, ambas, como fundamento humano de un mismo pensamiento, como integración vital de una misma unidad, NO.

Y así a Kant metafísico lo encontramos, como dijimos al comienzo en la "Crítica de Jå Rảón Práctica"̈. en la tealidad salvadora, palpitante y humana de la fe. ¿Ácaso no viyimos, ante todo, de anhelos y esperanzas, de alegrías yopenas? ¿Ácaso ho sufrió" también el filósofo de Koenigsberg? Que unos apunten cerca y otros lejos, pero todos apuntan emocionalmente, queriéndolo o no. El mismo Kant en los momentos de profunda abstraccićn especulativa, sentía, seguramente, la necesidad vital de supervivir por siempre, cuando escribía que "es inútil querer fingir indiferencia ante lo que no puede ser indiferente a la natura. leza humana". Sí, inútil querer fingir..., para Kant y para todo hombre que sienta el infinito anhelo de vida inacabable.

Que algunos encuentren al auténtico Kant en su Filosofía Teorética, y consideren a su Filosofía Crítica Práctica como un agregado secundario, no es posición capaz de armonizar con la conciencia humana, con los móviles profundos que determinan la acción y las ideas de los hombres. Nosotros pensamos más bien, que por haber sentido Kant, de manera avasalladora, la necesidad interior de salvar su fe, es que escribió su Filosofía Teorética. Es decir que la Filosofía Práctica está deter. 
minando a la Filosofía Teorética, cuya exposición no habría sido posible sin una referencia constante a la "Crítica de la Razón Práctica"; y así ésta, no sólo es complemento, sino culminación y acabamiento de la Filosofía Kantiana.

Pensemos en la vida del Filósofo, y lo veremos tratando de amoldar su conducta a la "Crítica de la Razón Práctica"; lo oiremos dialogar interiormente con su propia razón, a la que dirá: "sólo quiero que no acuses de contradicción a los anhelos y aspiraciones que mi corazón y mi fe pueden hacer reales, pensándolos como posibles". Y la razón espe culativa, impotente, vencida por la fe, dejará vivir al filósofo y al hombre.

Para terminar, formulémosle a Kant las tres preguntas de la Metafísi$\mathrm{ca}, \mathrm{y}$ escuchemos sus respectivas respuestas:

- ¿Existe lo real?

- Sí. Es el NOUMENO. Captamos nada más que fenómenos, pero el fenómeno sin el noumeno sería un absurdo.

- ¿Se puede conocer lo real?

- La razón especulativa carece de los instrumentos adecuados para insinuarse en el campo del "noumeno", de lo "supra-sensible". Pero le es permitido a la naturaleza humana peneträr ese campo, mediante el uso práctico de la razón.

- ¿Cómo es brealioteca de Letras

- Estamos trágicamente condenados a no conocerlo nunca; aunque tampoco podemos evitar pensarlo siempre, realizarlo por la fe, para poder vivir...

DEMETRIO PALOMINO BECERRA. 